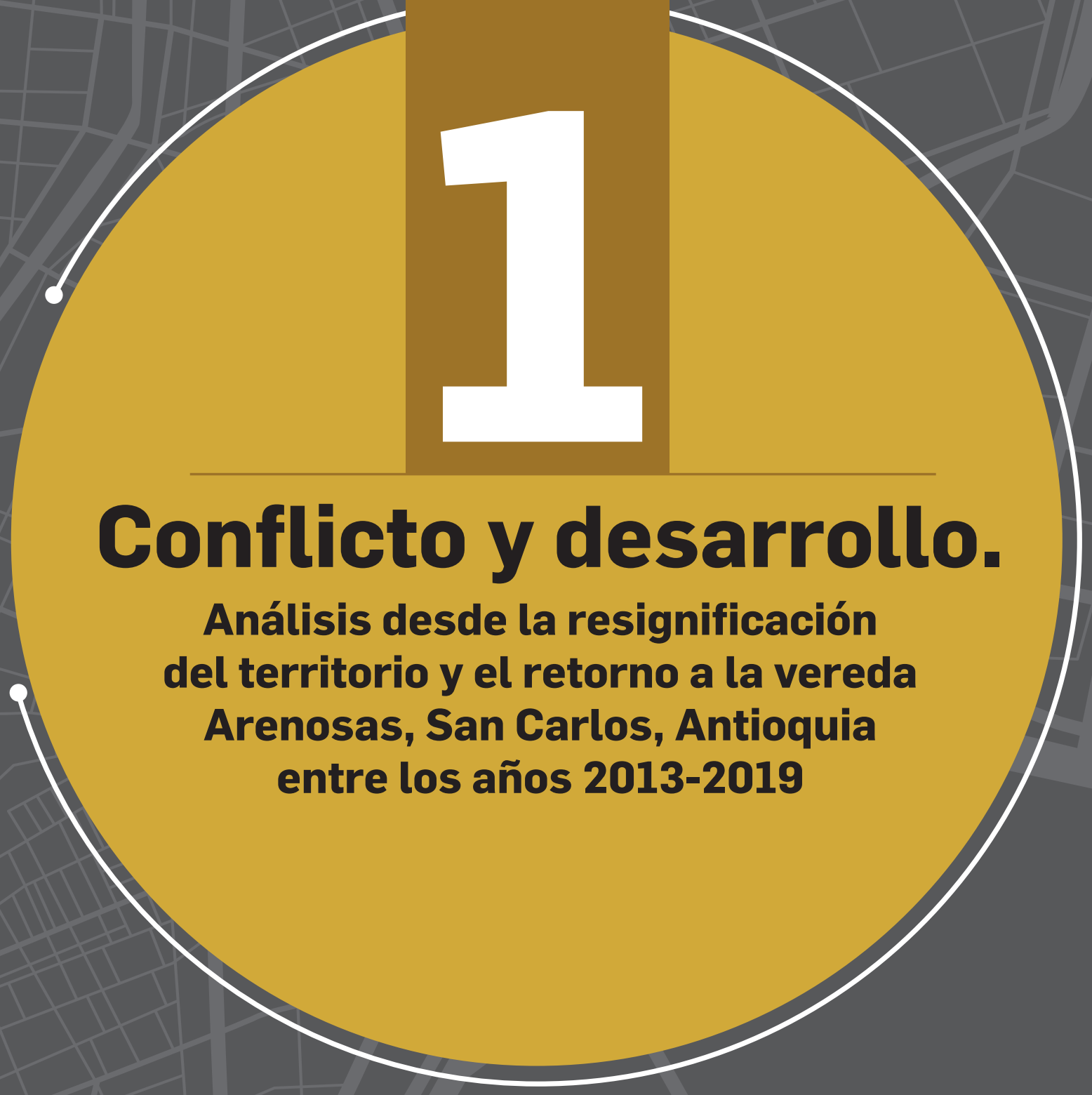

Andrés Felipe Vargas Giraldo Elkin Argiro Muñoz Arroyave 



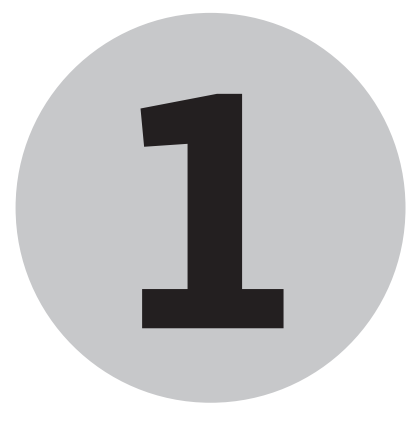

\section{Conflicto y desarrollo. Análisis desde la resignificación del territorio y el retorno a la vereda Arenosas, San Carlos, Antioquia entre los años 2013-2019}

Andrés Felipe Vargas Giraldo*

Elkin Argiro Muñoz Arroyave*

\section{Resumen}

El oriente antioqueño ha sido una de las regiones más golpeadas por el conflicto armado; sin embargo, también ha sido una región de un alto crecimiento económico por lo que ambos procesos han generado impactos sociales, económicos, políticos y ambientales. De esta manera, el presente capítulo ahonda en la comprensión de los procesos de resignificación territorial, asociados a la reconstrucción del tejido social y territorialidad en la vereda Arenosas del municipio de San Carlos, posterior al retorno de la población desplazada. A su vez, se indaga por la transformación de las lógicas de desarrollo, lideradas desde la población civil. Estas nuevas estrategias de desarrollo, en la vereda, se han visto como un impulso integral a procesos económico, sociales y políticos. La metodología empleada es cualitativa con una mirada crítica del desarrollo y amparada en técnicas como entrevistas semiestructuradas y recorridos territoriales. En tal

Palabras clave: desarrollo local, tejido social, territorialidades, territorio. sentido, se concluye que el proceso de resignificación de la comunidad está configurando una estrategia de desarrollo local, alrededor de la vinculación y armonización de sus potencialidades y capacidades territoriales, a través de la premisa del desarrollo integral y sostenible.

* Profesional en Desarrollo Territorial. Correo: andres.vargas1@udea.edu.co

** Economista, magíster en Desarrollo Regional y Planificación del Territorio, candidato a doctor en Estudios Territoriales. Docente investigador del Tecnológico de Antioquia Institución Universitaria. Correo: elkin.munoz@tdea.edu.co 


\section{Introducción}

os procesos de crecimiento económico que surgieron entre las décadas de los años 60 y 70, en la región del oriente antioqueño, generaron múltiples impactos sociales, económicos, políticos y ambientales, ante los cuales hubo protestas sociales que fueron reprimidas de manera violenta. Esta "represión de los movimientos cívicos en San Carlos se constituyó en el mito fundacional de la violencia. Un mito compartido que no genera divisiones entre los sancarlitanos" (Restrepo, 2009, p. 165). En tal sentido, desde la localidad se afirma que los fenómenos sociales vividos en la región, durante las décadas siguientes, están relacionados con los procesos de crecimiento económico. Por tanto, entender el desplazamiento forzado y todas las acciones victimizantes en el territorio, como una acción lineal que depende únicamente del conflicto armado, es un error ${ }^{1}$.

Es necesario comprender que las estrategias de crecimiento económico lideradas desde un modelo de desarrollo centralista pueden ocasionar, a su vez, transformaciones en las dinámicas territoriales. Así, el modelo de crecimiento económico, implementado entre los años 70 y 80 en Antioquia y Colombia, priorizaba intereses particulares de empresarios sobre las condiciones ambientales, sociales y económicas de los territorios. En esta medida, intervenciones en municipios como San Carlos y en todo el oriente antioqueño generaron tensiones locales que poco a poco fueron creciendo hasta que el conflicto armado las catapultó. Esto último dejó a la población civil del municipio desprotegida y con la presencia de nuevos actores locales que cambiaron drásticamente las dinámicas y lógicas territoriales.

1 El asentamiento de los grupos armados y la posterior agudización del conflicto no tiene un origen fortuito, sino que es sumamente necesario retornar hasta el periodo histórico de los años 70 y 80 , donde a partir de lógicas capitalistas asentadas en teorías de desarrollo económico dieron espacio para implementar un modelo económico sin análisis de contextos local y realidades territoriales en la subregión del oriente de Antioquia. 
San Carlos ha sido un municipio fuertemente golpeado por el conflicto armado, esto se puede ver en las cifras de víctimas del municipio en las últimas tres décadas (Ver Figura 1). El desplazamiento forzado fue una de las acciones victimizantes que más se profundizó en el municipio, hasta el punto de representar una expulsión de casi la mitad de su población durante los años de recrudecimiento del conflicto (1998-2005, como se puede ver en la Figura 1). Entre los años 2009-2011, se generó un proceso de retorno al municipio, momento en el que los actores sociales, como lo plasmaron durante el trabajo de campo, plantean posiciones diferentes frente al desarrollo, haciendo una resignificación del mismo y de su territorio.

Figura 1. Número de víctimas del conflicto en el municipio de San Carlos, 1985-2019.

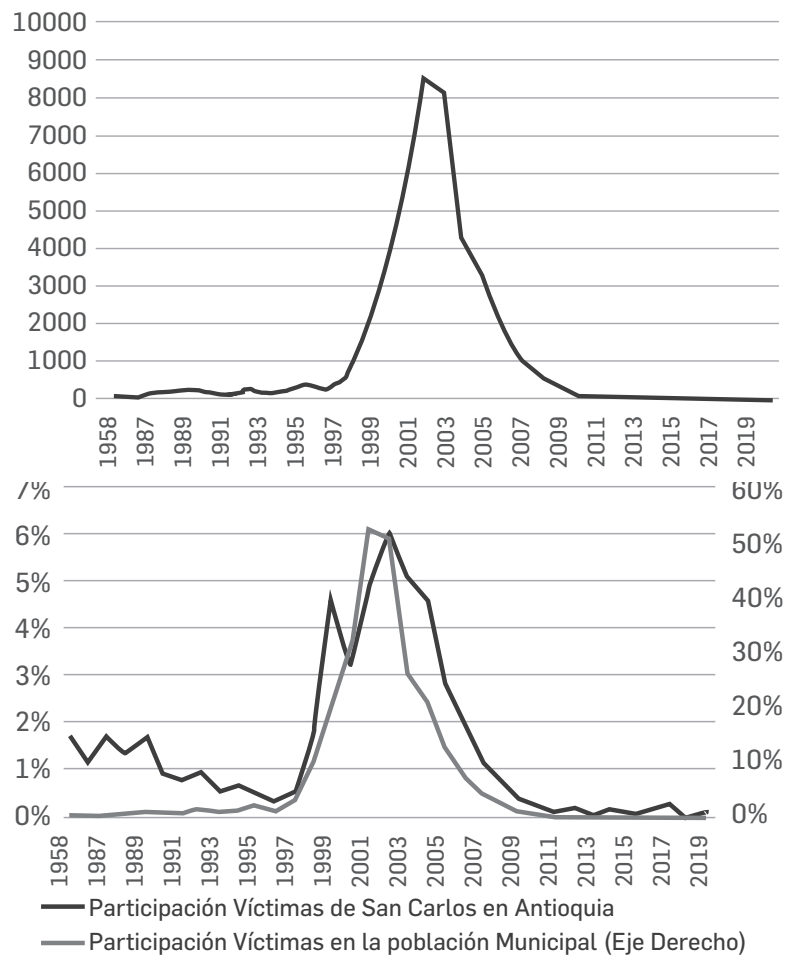

Fuente: Elaboración propia con base en DANE (2018) y Unidad de Víctimas (2020). 
En tal sentido, el objetivo de la investigación que se deriva en este capítulo fue indagar por los procesos de resignificación del territorio y las estrategias de desarrollo, a través de la reconstrucción de las distintas relaciones culturales y sociales de la población civil de la vereda Arenosas. En particular, se busca entender cómo han sido las trasformaciones de las dinámicas del desarrollo local posteriores al retorno. Para ello, se adelantó una metodología cualitativa con un enfoque sociocrítico ${ }^{2}$, basada en entender el territorio y el desarrollo como procesos construidos por los actores sociales locales. Así, las técnicas de investigación utilizadas se basaron en entrevistas semiestructuradas, recorridos territoriales, revisión documental y observación participante y no participante.

Se llevaron a cabo tres fases metodológicas. En la primera se procedió a la recolección de la información fundamentada en fuentes primarias, donde se hicieron ocho entrevistas semiestructuradas a la comunidad de la vereda Arenosas: seis con líderes sociales y dos con funcionarios del municipio de San Carlos. Además, se complementó con cuatro recorridos territoriales para tomar notas de campo y observar las actividades cotidianas de la población. Por otra parte, se tomaron fuentes secundarias como los informes institucionales: planes de desarrollo municipal, esquemas de ordenamiento territorial y proyectos presentados para el retorno de la población de San Carlos.

La segunda fase fue de sistematización, para lo cual se organizó la información a partir de las siguientes categorías de análisis: territorialidad, tejido social y desarrollo local. La última fase fue de triangulación de la información generada por los informes consultados y todo lo recogido en el trabajo de campo, mediante las entrevistas realizadas, haciendo el contraste con informes de autoridades e interacción con la comunidad de la vereda Arenosas.

2 Se desarrolló un contraste entre la comunicación activa con la población de la vereda Arenosas, en conjunción con los informes presentados por las instituciones encargadas del fortalecimiento social y económico en el territorio posteriormente al retorno. 
Este capítulo estará compuesto por tres secciones, además de las respectivas conclusiones y recomendaciones: en la primera, se presenta el apartado teórico y metodológico que acompañó el proceso de investigación; en la segunda, se hace una presentación de la unidad de análisis y algunas de sus dinámicas territoriales; en la tercera, se observan específicamente las estrategias y decisiones de los actores sociales de la vereda Arenosas, en San Carlos, que resignifican su proceso de desarrollo local.

\section{Aproximación teórica al desarrollo local y su resignificación}

La construcción teórica de la investigación estuvo relacionada con los actores sociales del municipio de San Carlos, su realidad y la forma como ellos mismos han tomado una posición frente al retorno, la memoria y las estrategias locales para mejorar las condiciones de vida. En este sentido, con base en la evidencia histórica, y en unión con los proyectos adoptados para el retorno, se forjan nuevas dinámicas de desarrollo a través de la adaptación de capacidades y contextos territoriales. Es así como se identificó el desarrollo local como el concepto central para esta investigación, el cual, a su vez, interactúa con otros conceptos derivados: territorialidad y tejido social. Estos tres conceptos no sólo guiaron este proceso investigativo, sino que también han sido las bases para el fortalecimiento de los procesos de retorno al municipio.

Los proyectos de desarrollo local que lideraron los actores retornados debían concentrarse en una implementación de acuerdo con el enfoque y las necesidades territoriales. Ante todo, debían conocer y reconocer quiénes eran los que habían sido desplazados para brindarle una atención adecuada, la cual les permitiera regresar al territorio sin ningún miedo de repetición, desde las prioridades de atención, reparación y no repetición.

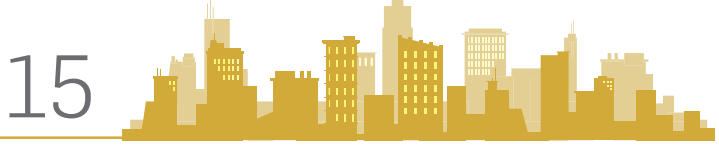


De este modo, entre estas prioridades, los líderes de los proyectos destacaban el hecho de lograr entregar herramientas a los habitantes para construir un proyecto productivo, el cual les permitiría empezar a formar parte de una actividad económica que no sólo tuviera incidencia en las finanzas personales, sino que también fuera parte de esa reactivación económica que necesitaba el municipio. En este punto, se está hablando de un proceso de desarrollo local, ya que son proyectos e ideas lideradas por actores del territorio que a través de sus acciones buscan resignificar los procesos de desarrollo vertical que se habían adelantado en el municipio de San Carlos.

Uno de los programas de retorno clave en el municipio fue el de Familias en su Tierra (FEST), el cual a través de una perspectiva de territorialidad y tejido social logró impulsar procesos de desarrollo local. Según el diálogo con los actores locales, este programa logró ser un proyecto de estabilidad y complementariedad para la construcción colectiva y social del territorio sancarlitano, estableciendo las bases esenciales para la proyección del desarrollo de énfasis local. El programa dispone de una serie de condiciones con el fin de implementar una visión potencial de atención integral, en este caso, y desde la mirada de esta investigación, se puede afirmar que tal programa prioriza el objetivo de la construcción de la territorialidad y el tejido social.

El programa FEST, busca contribuir a un proceso integral al interior de los territorios, basado en varias aristas estratégicas:

- Arraigo: establecer una relación intrínseca con el territorio, desde su conservación y su correcta gestión.

- Productividad: búsqueda de una estabilidad socioeconómica, gestionando proyectos acopladosa las potencialidades territoriales.

- Intervención del hábitat: mejoramiento de vivienda y promoción de las buenas prácticas al interior de ella. 
- Potencialización de la base social, creación de lazos fuertes de tejido social; a su vez, de manera simbólica, se propende la conservación de la memoria como un medio eficaz de lucha (Centro Nacional de Consultoría, 2016).

Este programa se efectuó con la finalidad de afianzar bases estratégicas de territorialidades y cohesiones sociales al interior de la comunidad afectada por el conflicto, para así configurar una sociedad con sentido de pertenencia, de apropiación, de confianza y de correspondencia y reciprocidad en los proyectos de carácter prospectivo que vayan a implementar como territorio. De este modo, a través de este programa se formaban los soportes de esos procesos de desarrollo que emergían en el territorio, donde se hace necesario desglosar y entender la complementariedad de los conceptos de desarrollo local, territorialidad y tejido social.

Teniendo esto en cuenta, a continuación, se discute la posición teórica que se asume frente a estos tres conceptos centrales. De esta forma, el tejido social funciona a través de la capacidad que posee la sociedad para agruparse con relación a objetivos en común, desde principios que busquen garantizar bienestares mancomunados (Téllez, 2010). Asimismo, este tejido social se consolida como el factor principal de agrupación interseccional entre las múltiples dimensiones que componen el territorio: "El tejido social está determinado mediante una base de recursos naturales, ciertas formas de producción, consumo e intercambio, y una red de instituciones y formas de organización que se encargan de darle cohesión al resto de los elementos" (Programa de la Naciones Unidas para el Desarrollo (PNUD), 2011, p. 35).

Partiendo de lo anterior, es posible afirmar que el tejido social funciona como la base esencial de los procesos enfocados en el desarrollo local de un territorio. La utilidad del tejido social está 
basada en una correspondencia social, es la posibilidad de agruparse y contribuir mutuamente a todos los miembros del grupo. A pesar de esto, la individualidad sigue siendo un elemento central para el actor social, ya que desde sus intereses y la obligación de satisfacer sus necesidades es que encuentra en el trabajo conjunto una oportunidad de crecimiento económico, social y político. En ese sentido, la individualidad también es un hecho de tejido social, la ambición y deseo de prosperar generan una intención de buscar personas con quién asociarse y vincular su proyecto a objetivos comunes.

La fortaleza del tejido social no solo se encuentra en la eficaz coordinación de esfuerzos para beneficiarse, sino también en cómo estar organizados para enfrentar conjuntamente los efectos colaterales que dispone la sociedad. Se desea conformar "unos entramados comunitarios enfocados a defender su territorio" (Gutiérrez, 2011, p. 37) de acciones irregularmente fomentadas y gestionadas por organismos institucionales ilegítimos que no toman en cuenta las opiniones y alternativas de acciones que podrían poseer la sociedad civil.

Por ello, es necesario potencializar y consolidar un tejido social estable territorialmente, una coalición interseccional de las múltiples dimensiones que conforman un territorio. Entre tanto, su coordinación transversal con el desarrollo local está caracterizada por algunas ventajas:

1. Explica mejor las relaciones intersectoriales y potencia el trabajo multidisciplinario.

2. Permite integrar los ejes fundamentales del desarrollo sostenible, es decir, los aspectos de organización económica, relación con el medio ambiente natural, organización social y política, a su vez, una articulación de los elementos culturales del territorio.

3. Permitegestionar el desarrollo más eficientemente, en colaboración entre actores locales. 
4. Potencia la integración de conocimiento acumulado por nuestras sociedades a fin de alcanzar un desarrollo armónico y democrático (PNUD, 2011, p. 36).

Por otra parte, la territorialidad es la relación entre las prácticas, actividades, costumbres y la articulación de las dimensiones que componen el territorio frente a la conexión con el sujeto social: "La territorialidad es esa relación dinámica entre todos los componentes sociales (economía, cultura, instituciones, poderes) y aquello que de material e inmaterial es propio del territorio donde se habita, se vive, se produce" (Dematteis y Governa, 2005, p. 33). La territorialidad se compone con una congruencia simétrica entre lugar/territorio y el sujeto que se apropia de este:

Los humanos transforman la tierra para convertirla en su casa, pero al hacerlo se transforman ellos mismos no sólo mediante la propia acción que implica esa transformación, sino también por los efectos que esa tierra transformada ocasiona sobre la sociedad humana (Delgado et al., 2001, p.16).

Esta proposición, señalada por el autor, acerca de la relación entre sujeto y lugar, está mediada por las prácticas que disponen al territorio a ser propio y diferenciarse frente a otros. Así, el resultado de una configuración territorial está encaminada a lo que el sujeto territorial decida convertir ese lugar. La apropiación y relación con los diferentes componentes sociales dan razón de ser al territorio. Las condiciones de un territorio están caracterizadas por las acciones que los actores sociales deciden implementar al interior de este, por medio de múltiples relaciones con su entorno social, económico, político, cultural y ambiental.

Se entiende, entonces, la territorialidad como una relación individual y/o colectiva con el territorio; se determina que tiene la capacidad de transformar un espacio a partir de relaciones dinámicas entre sujetos 
propios de ese territorio y foráneos. De tal modo, la territorialidad es un conjunto correspondiente entre decisiones e interacciones que eventualmente poseen implicaciones sobre el dinamismo del territorio.

De otro lado, el desarrollo local como alternativa surge a partir de los fallos de procesos de desarrollo clásicos, los cuales no focalizaban su atención a las necesidades, realidades y potencialidades territoriales. De esta manera, para los años 80 y 90 , se crearon alternativas de desarrollo con un mayor énfasis territorial, donde se proyectaba a los territorios desde sus mismas capacidades; además, de ser una forma para crear mecanismos más vinculantes, participativos y coherentes con las políticas de desarrollo territorial (Williner, Sandoval, Frías y Pérez, 2012).

El concepto de desarrollo local se constituye a partir de un enfoque territorial, en forma de reactivación de las capacidades territoriales propias e identitarias de los territorios. Siendo así, una alternativa de desarrollo, cimentada en la potencialización de una estrategia de adaptación a las contextualizaciones de los municipios, de tal forma que se prioriza la intención de configurar un territorio vinculante, participativo y ajustado con sus capacidades territoriales. De este modo, el desarrollo local se instaura como una construcción colectiva desde lo propio, con potencialidades y capacidades del mismo orden, con el fin de agrupar toda la contextualización territorial en alternativas que impulsen a todo lo que integre el territorio: "El desarrollo local se fundamenta en la consolidación de una economía al interior de un territorio; con instituciones, productores, sociedad y recursos que son propios de este espacio" (Boisier, 1999, p. 9).

Igualmente, la consolidación territorial está sustentada en la capacidad del sujeto social para proveerse de prácticas alternativas que fomenten el desarrollo local; además, de una capacidad asociativa para llevar a cabo, en forma de cohesión social, todos esos intereses y deseos del desarrollo desde su perspectiva local. El desarrollo local 
se consolida a partir de la esencia de la participación, de acuerdos multidisciplinares, del reconocimiento y del respeto por lo que habita territorialmente; además de incorporar iniciativas que se convierten en proyectos. La intención es integrar a todos en la construcción del proyecto de desarrollo local.

Es importante resaltar los aportes a la perspectiva del desarrollo local propuestos por autores como Vásquez (2009) y Alburquerque (2004), quienes muestran que el desarrollo local surge como una alternativa para la proyección de los territorios, desde el objetivo de dinamizar el capital social y las potencialidades territoriales, puesto que el desarrollo local hace parte del actuar social de quienes son, viven y conviven con el territorio. Como menciona Alburquerque (2004), el desarrollo local destaca esencialmente los valores territoriales, de identidad y diversidad; en ese sentido, estos valores se organizan como un soporte para la conformación de proyectos alternativos de enfoque local, los cuales se configuran a partir de las características de los territorios, desde visiones representadas por los consensos materializados a través de los particulares actores territoriales.

Además, desde la perspectiva del desarrollo local de Vásquez (2009), se señala a la cohesión social como primordial en la ejecución apropiada de los programas de desarrollo local; este último se caracteriza por agrupar un sistema social, institucional y cultural, los cuales interactúan entre sí (Vásquez, 2009). Adicionalmente, como lo describe Jorge Salinas, la ejecución del desarrollo local en un territorio puede tener implicaciones a través de iniciativas de gestión territorial, que posteriormente permite proyectar dinámicas productivas en las entidades locales. Entre algunos de los resultados de la ejecución del desarrollo local en un territorio, se encuentran los siguientes:

1. Valorización mayor de los recursos endógenos de cada ámbito local, tratando de impulsar actividades de diversificación productiva y promoción de nuevas empresas locales. 
2. Organización de redes locales entre actores públicos y privados para promover la innovación productiva y empresarial en el territorio.

3. Búsqueda de nuevas fuentes de empleo e ingresos a nivel local.

4. Promoción de actividades de desarrollo científico y tecnológico a nivel territorial.

5. Creación de nuevos instrumentos de financiamiento para atender a las microempresas y pequeñas empresas locales.

6. Superación de las limitaciones del enfoque asistencialista implícito en los fondos de inversión social y en los programas de lucha contra la pobreza (Salinas, 2000, p. 36).

Este concepto de desarrollo local busca promover la gestión territorial, siendo esta una de las formas en que se organizan las acciones a través de un plan común de intención territorial, desde un proceso de activación participativa que fomenta acuerdos mutuos entre los actores que convergen en el territorio. Asimismo, se provee la necesidad de configurar planes de acción orientados al buen uso y aprovechamiento de los recursos, desde los acuerdos de proyectos en común. Por lo tanto, la gestión territorial se podría definir como un proceso para instaurar un soporte para el desarrollo de capacidades adaptadas al contexto territorial, en vista de incentivar la participación y empoderamiento social de quienes viven y conviven particularmente en el territorio.

De esta manera, la gestión territorial implica conocer, reconocer y apropiarse de los componentes territoriales, de manera que los proyectos originados desde esta gestión involucran el uso sostenible y consciente de los recursos; además, de entablar acuerdos mutuos, donde la participación, el empoderamiento social y autonomía territorial sean las premisas de configuración territorial.

Finalmente, todos los conceptos se agrupan en la misma necesidad del territorio. La gestión territorial funciona como una herramienta 
para continuar con la estrategia del desarrollo local, lo que implica vincular al sujeto social en la planeación del uso coherente de su territorio, a partir del conocimiento, apropiación, participación y veeduría del desarrollo territorial implicado en su entorno.

\section{Dinámicas territoriales de San Carlos y la vereda Arenosas}

El municipio de San Carlos hace parte de la subregión del oriente de Antioquia (Ver Figura 2), siendo uno de sus 23 municipios, tiene una distancia de $108 \mathrm{Km}$ respecto a la ciudad de Medellín y $203 \mathrm{Km}$ con relación a Bogotá. Posee una temperatura media, entre 23 y 25 grados centígrados. Es un territorio rodeado de cascadas, ríos y otras fuentes hídricas, por lo que es uno de los municipios generadores de energía de Antioquia y del resto del país, aportando aproximadamente el 33\% de la energía nacional (Alcaldía Municipal de San Carlos, 2016). Su geografía se caracteriza por poseer un relieve quebrado de altas pendientes y gran riqueza hídrica.

Entre las 78 veredas que componen el municipio, se encuentra Arenosas, unaveredadondesupoblaciónfuedesplazada prácticamente en su totalidad. Está ubicada a $6 \mathrm{Km}$ del casco urbano del municipio. La vereda actualmente cuenta con aproximadamente 120 familias, 80 permanentes y 40 de veraneo. Concentra su economía en el cultivo de plátano y café, actividad complementada con la piscicultura y, en menor proporción, pero no menos importante, el sector de servicios, representados principalmente en el turismo, la pesca deportiva y el arrendamiento de fincas de veraneo (Secretario de participación social de San Carlos, comunicación personal, 2019). 
Figura 2. Localización municipio de San Carlos y vereda Arenosas.
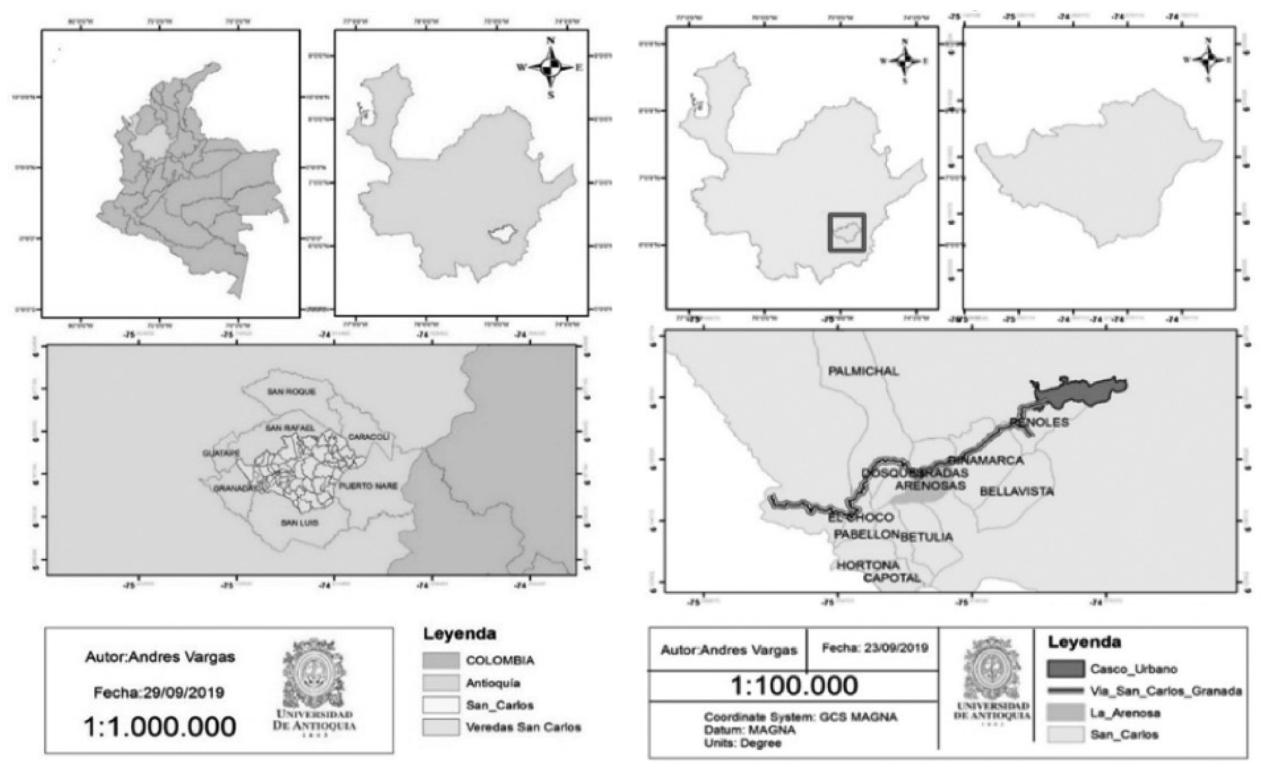

Fuente: Elaboración propia, 2019.

San Carlos es uno de los municipios más azotados por el conflicto armado en el país (Centro Nacional de Memoria Histórica (CNMH), 2014). Se calcula que cerca del $80 \%$ de su población salió desplazada entre los años de 1970 y 2005, dejando un perímetro urbano habitado por solo 4.000 o 5.000 personas aproximadamente, de las 25.500 registradas en el censo de 1993 (CNMH, 2011). Es necesario reconocer que los conflictos sociales en San Carlos se han presentado desde inicios de los años 70 y han sido ocasionados en mayor proporción por megaproyectos impuestos desde afuera y la lucha de poderes entre la acción armada insurgente y el poder del Estado. 
Desde los informes del Centro Nacional de Memoria Histórica se puede evidenciar que el proceso conflictivo tiene su génesis desde la construcción de importantes proyectos nacionales, como lo fueron los megaproyectos hidroeléctricos y la construcción de la Autopista Medellín-Bogotá (CNMH, 2011). Esto convirtió a San Carlos en un punto estratégico de presión estatal por parte de los grupos armados. El municipio se encargaba de la generación de cerca del 33\% de la energía del país, por tanto, controlarlo les daba a los grupos armados la posibilidad de ejercer un poder sobre el Estado (CNMH, 2011).

El desplazamiento en San Carlos no inició con la llegada de los grupos armados al territorio, comenzó desde la imposición de la estrategia de desarrollo nacional orientada hacia el incremento de la producción energética y el crecimiento económico, pero sin resultados de mejoramiento de condiciones de vida real a nivel local. Este desplazamiento data de los años 60 y 70, el cual se denominó "desplazamiento negociado", debido a que la venta de algunas zonas campesinas, en que se haría el proyecto hidroeléctrico, fueron negociadas por bajas cantidades de dinero, desproporcionadas a los precios reales (CNMH, 2011).

Posteriormente, para el año 1976 emerge en el territorio un movimiento social, llamado: Movimiento Cívico del oriente antioqueño. Este surge a partir de los altos costos en las tarifas de energía y la falta de inversión en el desarrollo local y regional. Además, alzaba su voz de protesta contra la corrupción en el manejo del dinero de las transferencias que generaba la producción energética. Desde la formación de este movimiento, se ampliaron las represiones de los grupos en el poder, de modo que no permitían la conformación de colectivos contradictorios a sus intereses económicos y políticos (Olaya, 2017).

En ese sentido, para el periodo entre 1978 y 1985, se generó el desplazamiento por parte de quienes hacían parte del Movimiento 
Cívico, los cuales huían del exterminio. Se había formado una estigmatización alrededor de quienes conformaban esta organización social, propiciando la fragmentación de los espacios de participación y organización social que generaba este grupo. A la postre, este actor social se convirtió en objeto de persecución, muerte, desplazamiento y exilio (CNMH, 2011).

De esta forma, el asentamiento potencial de grupos guerrilleros en el territorio surgió a partir de la recolección del descontento y el sentimiento de represión estatal que reflejaba parte de la población sancarlitana. Estos grupos se aprovecharon de tal situación, con el fin de tomar fuerza política en el territorio; del mismo modo, aumentando la fuerza armada, desde el discurso ideológico de reivindicaciones populares, con fundamentos de una transformación territorial. Así,

[v]arios investigadores de la región refieren la construcción de los embalses como uno de los factores que motivó a las guerrillas de las FARC y el ELN a instalarse en esta región, debido, por una parte, a los prometedores ingresos de estos megaproyectos, y, por otra, para defender a la población local de los atropellos cometidos contra ella (PNUD, 2010, p. 13).

Desde este punto, los grupos guerrilleros como el Ejército de Liberación Nacional (ELN) y las Fuerzas Armadas Revolucionarias de Colombia (FARC) se consolidaron territorialmente en San Carlos, con el objetivo de emprender su lucha contra el Estado con más fuerza. Asimismo, emergieron grupos contraguerrilla como las Autodefensas Unidas de Colombia (AUC), grupo proveniente del Magdalena Medio Antioqueño, el cual buscaba apaciguar el poder de los grupos guerrilleros y funcionar como un aliado del Estado en el territorio (CNMH, 2011). Por lo tanto, es importante recalcar que la confrontación armada no tiene un origen superficial de asentamiento fortuito; en parte, esto se debe a procesos mismos de represión 
estatal e imposiciones de estrategias de desarrollo que no conviven con las realidades de los espacios territoriales.

El municipio de San Carlos ha sido un hito del conflicto armado colombiano, siendo uno de los territorios más afectados por esta problemática socioeconómica. Por lo cual, es esencial reconocer esa historicidad del territorio, con el fin de evidenciar algunas situaciones que fueron causantes del conflicto armado experimentado años después. Por esta razón, en este caso, fue trascendental identificar la relación del conflicto armado con el asentamiento de proyectos nacionales, siendo una mezcla antagónica para los procesos sociales y el desarrollo local en el territorio.

Para el año 2005, en el municipio se inició un proceso institucional de retorno. Esto se hizo a través de un proyecto de carácter integral, es decir, el retorno no se realizó sólo atendiendo aspectos económicos, sino que se establecieron ideales de gestión para un retorno con enfoque social, político, de participación cultural y ambiental, para que el proceso fuera sostenible a través del tiempo (Corporación Jurídica Libertad, 2014). La intervención de las instituciones en la reconfiguración del municipio fue fundamental para el retorno de la población civil al territorio; entre ellas, cabe destacar la intervención de ayuda humanitaria internacional, la cual ha hecho un acompañamiento constante a la población afectada por el conflicto.

Igualmente, se hacía necesario entender las dinámicas territoriales, con el fin de brindar un buen manejo a las políticas, programas y proyectos de cooperación que fomentaban el retorno a los territorios (CNMH, 2011). Para el año 2007, se creó el Plan Integral Único (PIU), una institución encargada de hacer un diagnóstico de la situación de desplazamiento forzado en el municipio; además se complementó con la Unidad Coordinadora de Atención a la Población Desplazada (UCAD). Para la época emergieron gran cantidad de instituciones que 
buscaban velar por la responsabilidad social y el acompañamiento de las poblaciones coaccionadas por los grupos armados.

La idea fue priorizar a San Carlos, para ello se crearon acuerdos municipales, leyes nacionales y ordenanzas departamentales como municipio de paz, reconciliación y retorno. Asimismo, se gestionaron planes de acción con énfasis en el retorno, entre ellos se resaltan la Alianza Medellín-San Carlos (Alcaldía de Medellín, 2011), proyecto de Acompañamiento a procesos de retorno o reubicación del municipio de Medellín al Oriente antioqueño, financiado por la Alcaldía de Medellín y el Departamento de la Prosperidad Social y el Convenio de Retorno Alcaldía de San Carlos-Unidad para las Víctimas (Convenio 1510) (Mogollón y Gómez, 2015).

\section{Prácticas sociales y territoriales que resignifican el territorio de la vereda Arenosas}

San Carlos adoptó una perspectiva de resiliencia, basada en la resignificación de su territorio; se inició con un balance de retorno a este, poniendo los cimientos para los programas institucionales de retorno, siendo esto una forma para fortalecer los programas a través de la perspectiva de arraigo, rehaciendo la correspondencia entre territorio-comunidad, potencializando la base social, avivando el tejido social y cohesionando el territorio. Además, se despliega un modelo alternativo de desarrollo local, basado en una estructura de generación de valor territorial, desde cuatro líneas estratégicas transversales y correspondientes entre sí: 1 . Formas de reconocimiento, apropiación y manejo de los recursos territoriales. 2. Desarrollo de capacidades territoriales. 3. Alternativas de proyectos de desarrollo local desde engranajes comunitarios. 4. Autonomía territorial.

Durante la investigación de la que deriva el capítulo, se pudo evidenciar el rol esencial de la comunidad en la resignificación del 
territorio posteriormente al retorno, a su vez, se reflejaron los procesos de construcción colectiva de la estrategia de desarrollo local; todo esto, a partir de la gestión y planeación del territorio por parte de quiénes han vivido la historicidad o la conocen, y de quiénes conocen y reconocen sus capacidades como territorio. Creando en sí un sentido de correspondencia y cohesión social que vincula íntimamente la multiescalaridad $^{3}$ (Local, Regional, Nacional, Global) del territorio.

Una medida adoptada por los actores del territorio de San Carlos fue la memoria como estrategia de resignificación territorial y reconstrucción del tejido social ${ }^{4}$. La memoria se consolidó en el municipio como forma de conocerse y reconocerse en el marco de sus vivencias; además, fue una alternativa para vencer el miedo. Parte del valor de la memoria se sitúa en el no olvido, ejemplificando lo ocurrido con múltiples formas de visibilización. No es hablar de violencia o hacerle un recuerdo a ella, es representar su condición de afectados por la violencia, es no olvidar lo acontecido ni quiénes fueron afectados por esto, lo que significa que el "[...] ejercicio de la memoria individual y colectiva de las víctimas se constituye como una actividad fundamental para develar las injusticias sistemáticamente infringidas por los grupos armados" (Guerrero, 2016, p. 90).

Los procesos de memoria colectiva al interior del municipio dan cuenta de la resignificación del mismo concepto de memoria, el

3 La multiescalaridad es un principio básico para la comprensión de las distintas escalas de los territorios; por ejemplo, un territorio está organizado en una escala nacional, pero contiene territorios en escala departamental, regional y municipal (Cuervo et al., 2019).

4 La memoria es generada a partir de una construcción social, caracterizada por la interacción subjetiva de correspondencia social y cotidianidad territorial, las cuales, inciden en la disposición de los lazos sociales (Kuri, 2017). Es decir, la memoria puede funcionar como un medio de acción social, está constituida por valores subjetivos, desde la formación de una memoria colectiva e individual. La construcción social de la memoria se ejecuta como un medio de dignificación, resignificación y como una muestra de resiliencia en el proceso de los territorios. 
cual se funda como un concepto asociado a la resiliencia y no a la victimización. Así mismo, la memoria colectiva se fundamenta en los espacios de convivencia y diálogos de vivencias con el objetivo de fortalecer los lazos sociales, de respeto y obtención de triunfos frente al miedo; era una construcción social y conjunta de la memoria como hecho de fortaleza social. Así, "[l]a buena memoria permite aprender del pasado; porque el único sentido que tiene la recuperacion del pasado es que sirva para la transformación de la vida presente" (Coordinación CARE, San Carlos, comunicación personal, 20 de agosto de 2019).

En el municipio se ha consolidado una expresión artística que tiene como objetivo resaltar la identidad de San Carlos, más allá de la violencia sufrida (Ver Figura 3). Se trata de un movimiento muralista que intenta crear en el municipio un museo al aire libre con base en las imágenes que se plasman en las paredes locales. Esta iniciativa busca mirar desde otros puntos de vista el conflicto, saber qué ocurrió, como parte de la historia del territorio, pero que no define al territorio mismo. El territorio sancarlitano y sus actores sociales son mucho más que el conflicto vivido, estos murales intentan mostrarlo y consolidarlo, a través de la esperanza con nuevos mensajes que permitan resignificar lugares del miedo. 

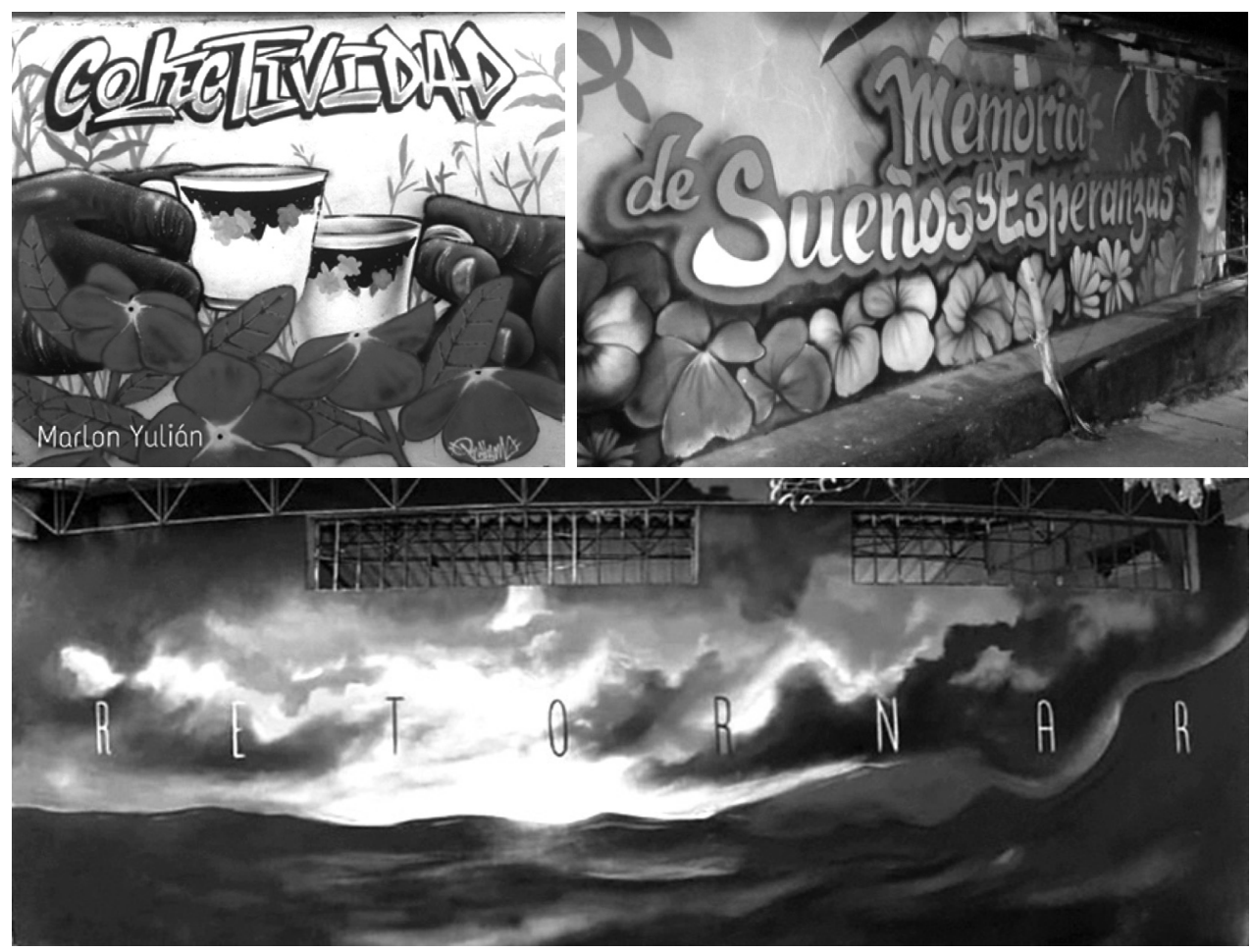

Fuente: Fotografías propias, 2019.

Por otra parte, la construcción del tejido social en la vereda Arenosas logró proyectar un territorio más estable, con una planeación basada en el trabajo multidisciplinar, que se logra fortalecer mediante nuevas ideas, otras perspectivas y posiciones frente a la toma de decisiones. Del mismo modo, el tejido social permite focalizar procesos de desarrollo local fundamentados en la gestión territorial. Incluso durante los momentos más álgidos del conflicto, el tejido social del municipio fue capaz de convertirse en un elemento importante para resistir territorialmente ante las acciones de los grupos armados y la fuerza pública (Rojas, 2018).

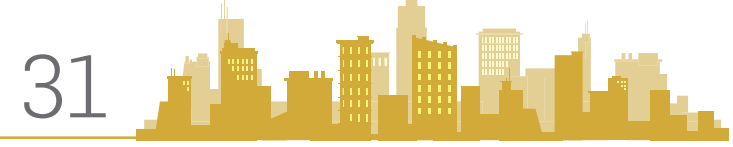


La conformación apropiada del tejido social permitió obtener incidencia en los procesos del desarrollo sostenible, asociado a los aspectos de organización económica, de relación con el medio ambiente natural, con la organización social y política; también de transversalizar una articulación con los elementos culturales del territorio. Esta consolidación de un tejido social potente concedió la habilidad de ampliar y legitimar esos proyectos o ideas que se tienen por parte de los actores sociales, permitiendo afianzar proyectos de focalización local que son innovadores e importantes para el territorio, pero no cuentan con asistencia técnica y/o presupuesto. Asimismo, el tejido social permite ampliar los espacios de diálogo y comunicación entre todos los actores territoriales, donde convergen culturas, identidades, ideales y deseos.

Desde el punto de vista de la territorialidad, la adecuada conjunción entre el sujeto social y el territorio que se habita, permite orientar proyectos con enfoques reales de apropiación, garantizando así una transformación basada en la conservación de la cultura, las prácticas, costumbres e ideologías, efectuadas en una simetría de correspondencia entre territorio y sujeto social. La territorialidad activa esa relación con el territorio que recrea poder y control sobre ellos; de esta manera, se permite crear acciones que favorezcan y privilegien las entidades territoriales. Es aquel sentimiento de arraigo, sentido de pertenecía, amor y respeto por el territorio, es un relacionamiento constante con el territorio que permite el conocimiento y reconocimiento de capacidades y necesidades locales. En este sentido, se crea consciencia y coherencia frente a las acciones que se toman alrededor de la entidad territorial.

El proceso de desarrollo local en la vereda Arenosas se constituyó desde la reactivación de sus capacidades territoriales; priorizando la promoción de una estrategia adaptable a las contextualizaciones de esta entidad territorial, con el fin de proyectarse mediante un 
modelo vinculante, participativo y adaptable con las potencialidades territoriales. De esta forma, en la comunidad de Arenosas se han logrado identificar una serie de recursos locales que pueden tener el potencial de generar ingresos para la comunidad. Para ello, y partiendo del tejido social construido, algunos actores han adelantado iniciativas económicas en pos de impulsar el desarrollo local.

Estasiniciativas están ancladas en la satisfacción de las necesidades locales, es decir, parte de identificar potenciales y debilidades de la comunidad para así impulsar los procesos de desarrollo. El primero de ellos tiene que ver con la implementación de huertas caseras como aporte a la seguridad alimentaria de la vereda. Las huertas realizadas en Arenosas se caracterizan por ser proyectos dirigidos en muchos casos por los programas institucionales de mejoramiento social posterior al retorno. De esta manera, las huertas son catalogadas como una oportunidad para volver a la tierra y mejorar el cultivo de los alimentos. Asimismo, en la creación de esta iniciativa de seguridad alimentaria, se establecen una serie de características mínimas que deben tener o promover estas huertas:

- La huerta debe ser una forma de integración familiar; de esta manera, se presume la reconstrucción en familia y la posibilidad de asignar una responsabilidad conjunta orientada hacia el cuidado de la huerta.

- El buen uso de la tierra y del entorno alrededor de la huerta. De este modo, se intenta mejorar la alimentación de la familia en cuestión de alimentos más sanos, producidos de manera ecológica y generando la calidad de ellos.

- Volver a las semillas nativas y a la utilización de fertilizantes naturales.

- Prevenir la erosión y repeler plagas mediante plaguicidas ecológicos. 
El otro proceso que busca dinamizar el desarrollo local es el de una iniciativa de turismo ecológico. Con esta iniciativa se busca utilizar los recursos naturales, históricos y culturales de la vereda y del municipio en pos de la atracción turística. Es importante resaltar que el turismo sostenible en el territorio no es un asunto de unos pocos, esto permite agrupar la identidad y el tejido social como factores esenciales para la construcción de esta estrategia de desarrollo local. Del mismo modo, se señala que este turismo permite crear sostenibilidad no solo desde un aspecto ambiental, sino también de apropiación cultural, identitaria, social y, a su vez, desde lo económico, debido a que caracteriza la autonomía de ciertas comunidades para que dirijan, desarrollen y se vinculen integralmente al proceso turístico del territorio, subsanando, así, parte de las dificultades económicas que se puedan presentar.

Adicionalmente, se debe señalar que este proyecto turístico es construido a través de una red social de actores territoriales que contribuyen desde sus capacidades y conocimientos a la estabilización y consolidación territorial de este proyecto turístico (Ver Figura 4). En la red identificada se puede ver que aún hay espacio para seguir afianzándola, hay una participación relativamente amplia, pero los actores aún tienen pocas relaciones entre sí, se esperaría que en la medida que se afiance el proceso turístico, la red también pueda volverse más compacta y la información pueda fluir más claramente. De tal manera, se entiende que no es un proyecto fortuito y de trabajo individual, sino que es un trabajo mancomunado entre varios actores institucionales: transporte, salud, seguridad y servicios de alojamiento y alimentación. En general, es una red que trabaja a través de objetivos comunes por el desarrollo local del municipio de San Carlos. 
Figura 4. Red de actores alrededor del proceso turístico.

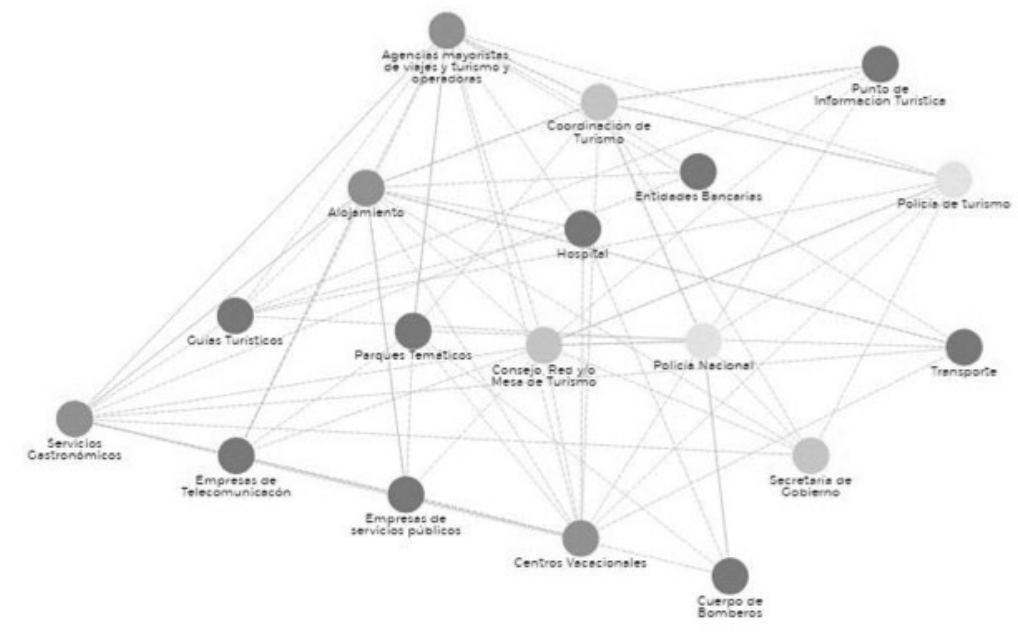

Tipo

Comercio Administración pública Servicios Seguridad

Fuente: Elaboración propia, 2019.

Es importante resaltar la capacidad de resiliencia evidenciada en la voluntad y en la fuerza que ha tenido cada líder social, los cuales han emprendido alternativas fundamentales de resignificación a través del arte, el respeto, la integración social, la apropiación e intención constante de potencializar el territorio en temas de desarrollo local, con orientaciones hacia la conservación, integración multisectorial, sostenibilidad y autonomía de su proyección municipal. Este proceso resignificante, se consolida como un gran ejemplo para otros territorios que han sufrido el conflicto armado. De esta manera, el proyecto también deja dudas e ideas de cómo se logra englobar proyecciones en los territorios a partir de las particularidades y potencialidades locales. 
En este orden de ideas, lo que se observa es que el proceso de desarrollo local en la vereda Arenosas se constituyó a partir de un enfoque territorial, desde la reactivación de sus capacidades. De esta forma, en la vereda, se estableció seguir construyendo esta estrategia de desarrollo local a través de la construcción colectiva de lo propio, con potencialidades y capacidades del mismo orden, con el fin de agrupar toda la contextualización territorial en alternativas que impulsen a todo lo que integre el territorio; adicionalmente, se permitió proyectar a la vereda como un referente visible localmente.

De igual manera, en el momento de la construcción de estas alternativas promovidas por los habitantes de la vereda Arenosas, se establece la legitimidad e integralidad como factores transcendentales. En este sentido, estos programas van orientados hacia el afianzamiento del desarrollo local a partir de la esencia de la participación, reconocimiento y respeto por lo que habita territorialmente, de iniciativas que se convierten en proyectos.

Finalmente, estos procesos efectuados en el trascurso de las alternativas de desarrollo local están representados por un pacto social territorial. Estos pactos buscan cambiar las formas tradicionales en que se presenta el desarrollo de los municipios, las cuales estaban fundamentadas en la verticalidad, mientras los procesos de desarrollo local se sustentan en la representación de la horizontalidad. Del mismo modo, se trata de priorizar el concepto desde un modelo de abajo hacia arriba, estableciendo al sujeto social como elemental en la construcción de un desarrollo local adaptado más a las focalizaciones territoriales, a razón de que el sujeto conoce, reconoce y se apropia de todas las capacidades territoriales.

\section{6}




\section{Conclusiones}

Se resalta que el desarrollo local no es meramente una representación de sistemas económicos dentro de los territorios; en realidad propende por ser una alianza intrínseca comunitaria, que da valor a los sentidos culturales, sociales y ambientales. De esta manera, es esencial reconocer el aporte significativo del tejido social y la territorialidad en la consolidación de una estrategia de desarrollo local. Asimismo, la implementación de estas alternativas de desarrollo local, permitieron emprender un enfoque particularizado por parte de las comunidades, siendo así, un enfoque que consolidará la posibilidad de ejecutar proyectos dirigidos por quienes conocen sus realidades, sus potencialidades y características como territorio, con el fin de agruparlas no como problemáticas sociales, sino como estrategias de proyección territorial.

Igualmente, el desarrollo local se convierte en una alternativa potencial en los territorios donde el proceso de intervención estatal es reducido, dándole una importancia a la implementación de proyectos desde un origen comunitario, lo cual permite potencializar el tejido social, así como la acción de correspondencia, confianza, participación, legitimidad y, lo más esencial, territorialidad; toda la progresión de los proyectos y programas de desarrollo local están fundamentados en su contexto territorial. Siendo proyectos pensados, coordinados, gestionados e implementados por el sujeto que vive, convive con y en el territorio.

De este modo, la estrategia de desarrollo local ejecutada está permitiendo la vinculación activa de todos los actores territoriales desde la implementación de programas de retorno que buscan incrementar la participación comunitaria en los procesos de desarrollo local del territorio. Al ser este heterogéneo, tanto en sus prácticas, 
su identidad como en su situación natural, es necesario hacer una caracterización específica de capacidades dentro de la misma vereda.

Adicionalmente, el desarrollo local se presenta como una alternativa viable en la conformación de una entidad territorial estable, participativa, visionaria y con objetivos estratégicos de intervención claros y legítimos. Además, se vincula la planificación de esta estrategia de desarrollo como un proceso constructivo de rechazo a los modelos del pasado que impactaron en la sociedad, con el fin de emprender nuevas metodologías, iniciativas e ideas que evidencien el nuevo significado y la construcción colectiva que se está trasmitiendo alrededor del territorio.

Finalmente, se debe resaltar que el conflicto armado en Colombia ha traído consecuencias severas para diferentes territorios. $\mathrm{Ha}$ generado una fragmentación de las comunidades, un desarraigo de las personas y una pérdida de confianza en las instituciones estatales. Todo ello, sin lugar a duda, limita el desarrollo de la nación. Sin embargo, lo que han mostrado los territorios más fuertemente golpeados por la violencia es que hay una oportunidad de recomponer el tejido social, resignificar los espacios del miedo que crearon las acciones violentas $y$, en mayor medida, resignificar el desarrollo que se ha basado en imposiciones centralistas hacia un desarrollo pensado desde los territorios y actores sociales. Estos territorios han mostrado que no se trata de actuar como si no hubiera ocurrido nada, sino en hacer una reconstrucción de la memoria que le permita al territorio seguir adelante y que sus actores sociales lideren nuevos procesos de desarrollo. 


\section{Referencias}

Alburquerque, F. (2004). Desarrollo económico local y descentralización en América Latina. Revista de la CEPAL, 82, 157-171.

Alcaldía de Medellín. (2011). Reconstrucción de la experiencia alianza Medellín - San Carlos piloto: Modelo territorial de acompañamiento a retornos colectivos (2009-2011). Medellín, Colombia: Alcaldía de Medellín.

Alcaldía Municipal de San Carlos. (2016). Plan de Desarrollo 20162019. Antioquia: Alcaldía de San Carlos.

Boisier, S. (1999). Desarrollo (local): ¿de qué estamos hablando?. Revista paraguaya de sociología: publicaciones sociales para América Latina, 36, 7-29.

Centro Nacional de Memoria Histórica. (CNMH). (2011). San Carlos: memorias del éxodo de San Carlos. Colombia: Aguilar, Altea, Taurus, Alfaguara.

Centro Nacional de Memoria Histórica. (CNMH). (2014). San Carlos: memorias del éxodo en la guerra. Resumen. San Carlos (Antioquia, Colombia). Colombia: Centro Nacional. Recuperado de www.bibliotecadigitaldebogota.gov.co/resources/2079120/

Centro Nacional de Consultoría. (2016). Informe de resultados de la evaluación y tercera entrega de la documentación de las bases de datos. Bogotá: Centro Nacional de Consultoría y E-valuar.

Corporación Jurídica Libertad. (2014). Procesos de retorno al oriente antioquieño: "Retornar dignamente o volver sin derechos". Estudio de caso. Recuperado de https://cjlibertad.org/files/Proceso_de_ Retorno_al_Oriente_Antioqueo_Estudio_de_caso.pdf 
Cuervo, L., y Délano, M. (Eds.). (2019). Planificación multiescalar: ordenamiento, prospectiva territorial y liderazgos públicos. Volumen III. Santiago: CEPAL.

DANE. (2018). Series de población 1985-2020. Recuperado de https://www.dane.gov.co/index.php/estadisticas-por-tema/ demografia-y-poblacion/series-de-poblacion

Delgado, M., Moncayo, E., Jiménez, L., Carrizosa, J., Osorio, L., Escobar, L., ... Zárate, C. (2001). Espacios y territorios. Razón, pasión e imaginarios. Bogotá, Colombia: Universidad Nacional de Colombia.

Dematteis, G., y Governa, F. (2005). Territorio y territorialidad en el desarrollo local. La contribución del modelo SLOT. Boletín de la A. G. E., 39, 31-58.

Gutiérrez, R. (2011). Pistas reflexivas para orientarnos en una turbulenta época de peligro. En R. Gutiérrez. (Ed.), Palabras para tejernos, resistir y transformar en la época que estamos viviendo (pp. 31-55). Cochabamba, Bolivia: Textos Rebeldes.

Guerrero, H. (2016). San Carlos: Un modelo de conexión social en medio de la violencia. Trans-Pasando Fronteras, 8, 85-94.

Kuri, E. (2017). La construcción social de la memoria en el espacio: una aproximación sociológica. Península, 12(1), 9-30.

Mogollón, G. y Gómez, G. (2015). Retorno a San Carlos: la comunicación pública como activo dinámico de la gobernanza (Tesis de Maestría). Universidad EAFIT, Medellín, Colombia.

Olaya, C. (2017). El exterminio del Movimiento Cívico del Oriente de Antioquia. El Ágora USB, 17(1), 128-144. doi: https://doi. org/10.21500/16578031.2815

Programa de la Naciones Unidas para el Desarrollo. (PNUD). (2010). Oriente antioqueño: análisis de la conflictividad. 
Recuperado de https://info.undp.org/docs/pdc/Documents/ COL/00058220_Analisis\%20conflictividad\%200riente $\% 20$ Antioque\%C3\%B1o.pdf

Programa de la Naciones Unidas para el Desarrollo. (PNUD). (2011). Colombia rural, razones para la esperanza. Bogotá, Colombia: INDH-PNUD.

Restrepo, G. (2009). Memoria e historia de la violencia en San Carlos y Apartadó. Universitas Humanística, 72(72). Recuperado de https://revistas.javeriana.edu.co/index. php/univhumanistica/article/view/2151

Rojas, J. (2018). Tejido social y resistencia en San Carlos-Antioquia (Tesis de Maestría). Universidad Nacional de Colombia, Bogotá, Colombia.

Salinas, J. (2000). Desarrollo turístico en el municipio de Buena Vista, Santa Cruz, Bolivia: desafíos y opciones para impulsar un proyecto de desarrollo local. Santiago de Chile: CEPAL.

Téllez, I. (2010). El sentido del Tejido Social en la construcción de comunidad. Polisemia, 10, 9-23.

Unidad de Víctimas. (2020). Víctimas del Conflicto Armado. Colombia: Red Nacional de Información. Recuperado de https://cifras. unidadvictimas.gov.co/Home/Vigencia

Vásquez, A. (2009). Desarrollo local, una estrategia para tiempos de crisis. Apuntes Del CENES, 28(47), 117-132. Recuperado de https:// revistas.uptc.edu.co/index.php/ cenes/article/view/83

Williner, A., Sandoval, C., Frías, M., y Pérez, J. (2012). Redes y Pactos sociales territoriales en América latina y el caribe: sugerencias Metodológicas para su construcción. Santiago de Chile: CEPAL. 


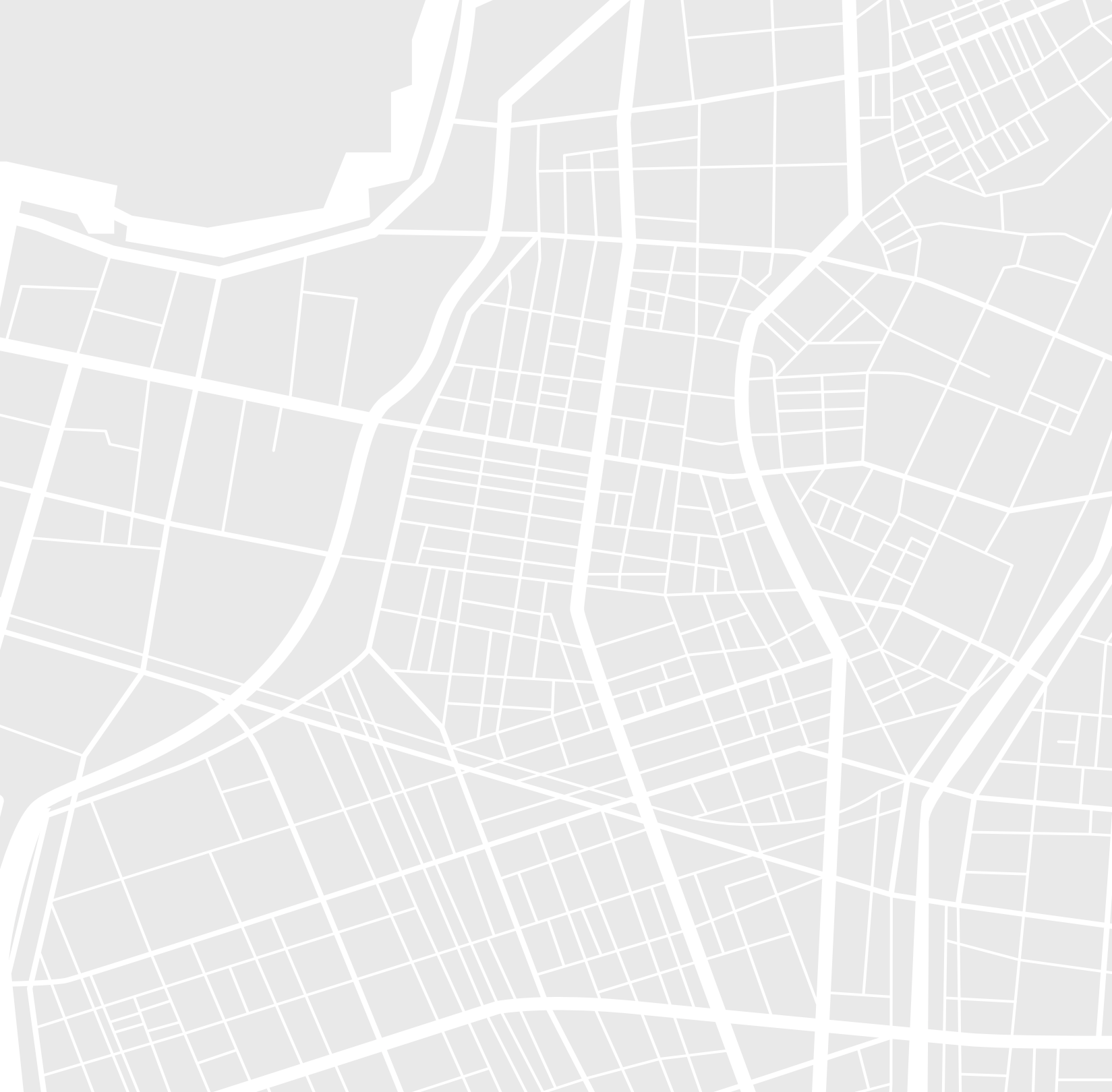

